Article

\title{
pH Responsive Abelmoschus esculentus Mucilage and Administration of Methotrexate: In-Vitro Antitumor and In-Vivo Toxicity Evaluation
}

\author{
Sobia Noreen 1,*(D), Sara Hasan ${ }^{1,2}$, Shazia Akram Ghumman ${ }^{3}$, Syed Nasir Abbas Bukhari ${ }^{4, *}$, Bushra Ijaz ${ }^{5}$, \\ Huma Hameed ${ }^{6}$, Huma Iqbal ${ }^{1}$, Afeefa Aslam ${ }^{3}$, Mervat Abdelaziz Mohamed Elsherif ${ }^{7}$, Shazia Noureen ${ }^{1}$ \\ and Hasan Ejaz ${ }^{8}$ (D)
}

check for updates

Citation: Noreen, S.; Hasan, S.; Ghumman, S.A.; Bukhari, S.N.A. Ijaz, B.; Hameed, H.; Iqbal, H.; Aslam,

A.; Elsherif, M.A.M.; Noureen, S.; et al. $\mathrm{pH}$ Responsive Abelmoschus esculentus Mucilage and Administration of Methotrexate: In-Vitro Antitumor and In-Vivo Toxicity Evaluation. Int. J. Mol. Sci. 2022, 23, 2725. https://doi.org/ $10.3390 /$ ijms 23052725

Academic Editor: Helena Felgueiras

Received: 31 December 2021 Accepted: 21 February 2022 Published: 1 March 2022

Publisher's Note: MDPI stays neutral with regard to jurisdictional claims in published maps and institutional affiliations.

Copyright: (c) 2022 by the authors Licensee MDPI, Basel, Switzerland. This article is an open access article distributed under the terms and conditions of the Creative Commons Attribution (CC BY) license (https:// creativecommons.org/licenses/by/ $4.0 /)$.
1 Institute of Chemistry, University of Sargodha, Sargodha 40100, Pakistan; ssarahhsn@gmail.com (S.H.); humaiqbal203@gmail.com (H.I.); shazianoureen11@gmail.com (S.N.)

2 Department of Chemistry, Sargodha Campus, The University of Lahore, Sargodha 40100, Pakistan

3 College of Pharmacy, University of Sargodha, Sargodha 40100, Pakistan; shazia.akram@uos.edu.pk (S.A.G.); afeefa_aslam@yahoo.com (A.A.)

4 Department of Pharmaceutical Chemistry, College of Pharmacy, Jouf University, Sakaka 72388, Saudi Arabia

5 Centre of Excellence in Molecular Biology, University of the Punjab, Lahore 54000, Pakistan; bijaz@cemb.edu.pk

6 IRSET, EHSEP, INSERM, University of Rennes 1, 35000 Rennes, France; huma4748@gmail.com

7 Chemistry Department, College of Science, Jouf University, Sakaka 42421, Saudi Arabia; maelsherif@ju.edu.sa

8 Department of Clinical Laboratory Sciences, College of Applied Medical Sciences, Jouf University, Sakaka 72388, Saudi Arabia; hetariq@ju.edu.sa

* Correspondence: sobia.noreen@uos.edu.pk (S.N.); sbukhari@ju.edu.sa (S.N.A.B.); Tel.: +966-5657-38896 (S.N.A.B.)

\begin{abstract}
The rapid progression in biomaterial nanotechnology apprehends the potential of nontoxic and potent polysaccharide delivery modules to overcome oral chemotherapeutic challenges. The present study is aimed to design, fabricate and characterize polysaccharide nanoparticles for methotrexate (MTX) delivery. The nanoparticles (NPs) were prepared by Abelmoschus esculentus mucilage (AEM) and chitosan (CS) by the modified coacervation method, followed by ultra-sonification. The NPs showed much better pharmaceutical properties with a spherical shape and smooth surface of 213.4-254.2 nm with PDI ranging between 0.279-0.485 size with entrapment efficiency varying from $42.08 \pm 1.2$ to $72.23 \pm 2.0$. The results revealed NPs to possess positive zeta potential and a low polydispersity index (PDI). The in-vitro drug release showed a sustained release of the drug up to $32 \mathrm{~h}$ with $\mathrm{pH}$-dependence. Blank AEM -CS NPs showed no in-vivo toxicity for a time duration of 14 days, accompanied by high cytotoxic effects of optimized MTX loaded NPs against MCF-7 and MD-MBA231 cells by MTT assay. In conclusion, the findings advocated the therapeutic potential of AEM/CS NPs as an efficacious tool, offering a new perspective for $\mathrm{pH}$-responsive routing of anticancer drugs with tumor cells as a target.
\end{abstract}

Keywords: biopolymer; anticancer drug; sustained delivery; $\mathrm{pH}$-responsiveness; in-vivo toxicity; antitumor activity

\section{Introduction}

The potential to attain efficacious therapeutic dosage with minimal perils has taken precedence for researchers in the recent decade. Nonetheless, the prevailing itineraries to cancer treatment, such as chemotherapy still require many refined routes to attain the best results in response to traditional drugs. The nano-scaling of chemotherapeutics whilst encapsulating them within carriers with stimuli-responsive aptitude seems to be a probable route to tackle shortcomings. The engineering of such carriers to respond to certain stimuli promises targeted delivery of anticancer drugs to tumor cells by establishing endosomal 
uptake and adornment with targeting agents. Such stimuli-responsive nanocarriers have the potential to trigger the release of cargo (drug) enclosed within once they reach the tumor site, in response to particular stimuli for instance $\mathrm{pH}$, hypoxia, and overexpression of certain enzymes [1,2].

In this smart nanomaterials research decade, the tide has shifted largely towards biodegradable polymers, polysaccharides and lipids. Polysaccharide nanoparticles (PNPs), in addition to nano-ranged size, have the potency to procure a sustained payload release, attuning their composition to preeminent outcomes [3]. Moreover, their inherent properties, such as abundance, non-cytotoxicity, biodegradability, low cost, biocompatibility have improved their use in fabricating drug delivery modules, particularly for anticancer drugs encapsulation [4,5]. Polysaccharides, such as chitosan [6], hyaluronic acid [7], dextran [8], alginate [9], Angelica sinensis [10], and fucoidan [11] nanocarriers have been devised as anticancer agents and demonstrated to not only have the potential to curtail the hazards but also acquire adequate therapeutic indices with minimal side effects.

Abelmoschus esculentus mucilage (AEM), natively known as okra gum, is an anionic polysaccharide that includes a dominant blend of galactose, rhamnose and glucuronic acid monomers. It has been widely used as a drug excipient, binder, film-forming and drug delivery agent with an acetylation degree (DA = 58) [12]. Chitosan $(C S)$ is an abundant cationic polysaccharide obtained by alkaline chitin deacetylation. It offers broad therapeutic applications varying from the manufacturing of food to targeted cellular payload delivery. The extensive use of CS in NPs is indebted to its cationic nature which aids in plummeting the circulation period and amplifying bioavailability upon biological environment exposure [13]. Furthermore, it shows the excellent permeability of encapsulated drugs due to its ability to open tight junctions between epithelial cells [14]. The efficacy of CS-NPs is often improved by their tailoring with anionic polysaccharides that have shown to decrease their macrophagal uptake, enhancing the efficacy of the encapsulated cargo [15]. Moreover, both AEM and CS polymer-based nanocarriers are known to give effective protection against gastrointestinal degradation. As a result, they increase bio-sorption owing to their bioadhesive nature, encouraging their use in site-specific delivery devices [16,17]. For instance, AEMCS NPs have been found to possess an excellent mucoadhesive character with targeted delivery of esculin. Likewise, thiolated AEM-NPs have proven to be a compelling drug carrier with target precision to the brain conceding its potential in delivery systems [18].

Methotrexate (MTX), a folic acid antagonist has been in clinical instrumental use for cancer and autoimmune diseases. It inhibits folic acid metabolism by blocking the activity of dihydrofolate reductase by interfering in the de novo synthesis of DNA, RNA and proteins $[19,20]$. However, its therapeutic efficacy is often seriously compromised by its insignificant targeting tendency that often leads to side effects, such as alopecia, nausea, body aches, hepatotoxicity and myelosuppression [21]. The poor targeting capability and low bioavailability of MTX can be boosted by its encapsulation within nanocarriers [22] Although, in the past decade, several natural polysaccharides based nanocarriers for MTX targeted delivery have been developed. For instance, phytic acid and CS-based NPs by ionic gelation for MTX controlled release, were formulated by Ciro et al., [23]. Wang et al., (2021) prepared lactobionic modified thymine and CS comprised nanocarriers for MTX [24]. A biodegradable nanocarrier based on CS and silica was synthesized by Shakeran et al., for the treatment of breast cancer [25]. Bhattacharya formulated polymeric lipid hybrid NPs for glioma treatment by MTX [26]. However, the preparation steps involved in such NPs are complex and most of these require the addition of a cross-linker. Additionally, such delivery modules require organic solvents in their synthesis pathway posing toxicity and protein denaturation. In an attempt to selectively deliver MTX payload to tumor physiological environment, with minimal toxicity level, to normal cells we prepared AEM-CS NPs by a slightly modified coacervation method. The method utilized was simple as it allowed self-crosslinking of polymeric matrix followed by electrostatic interactions of MTX. The characterizations of the resulting nanoparticles regarded size, shape and encapsulation efficiency. MTX release profiles at gastrointestinal $\mathrm{pH}$ (1.2 and 7.4) and tumor $\mathrm{pH}(5.5)$ were 
studied to ensure the targeting capability of NPs as pH-responsive nanocarriers. We also exposed MCF-7 and MD-MBA231 cell lines and non-cancerous Vero cells to MTX/AEMCS NPs for cell viability evaluation which showed that MTX/AEM-CS NPs could be a potential alternative to commercial anticancer drugs, alongside the provision of side-effect free chemotherapeutics.

\section{Results and Discussion}

Low bioavailability and interaction with normal cells are the major concerns associated with cancer therapeutics. A solution to these inadequacies seems to be the utilization of encapsulation of cancer drugs with natural polymers with efficient methods. AEM and CS were chosen as carriers for MTX delivery because of their safe, biodegradable and biocompatible nature.

Inter-chain bonding between AEM (anionic polymer) and CS (cationic polymer) led to the formation of electrostatic interactions, demonstrated in Figure 1. Moreover, weak electrolyte formation between CS and AEM led to a lowering of the free system energy which augmented the overall complex stability as discussed in another study [27].

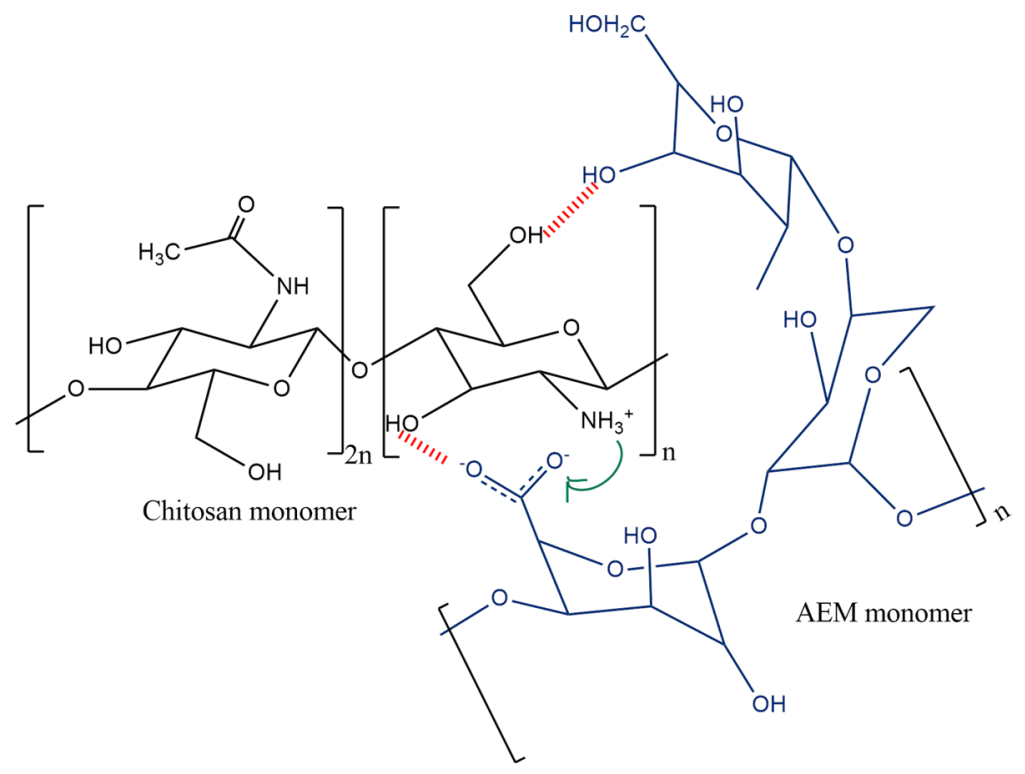

Figure 1. Electrostatic Interaction between AEM and CS monomers.

The present study was carried out with the aim that AEM-CS based formulations would enable the chemotherapeutics to be used to their full therapeutic potential in controlled ways whilst alleviating the toxicities associated with them. Moreover, the encapsulation of MTX with AEM mucilage would enable these nanoparticles to be delivered orally as it would provide protection from the gastric environment. For it, several formulations (F1, F2, F3) were prepared with varying concentrations of AEM and CS in ratios of 2:1, 1:1, $1: 2$, respectively. Methotrexate was used as a model drug at a concentration of $1 \mu \mathrm{g} / \mathrm{mL}$.

\subsection{FTIR Spectroscopy}

The two charged polymers interacted to form a polyelectrolyte complex which was characterized by FTIR. The absorption peaks of MTX shown in Figure $2 \mathrm{~d}$ at $3766.98 \mathrm{~cm}^{-1}$ and $3564.45 \mathrm{~cm}^{-1}$ indicated imines and $\mathrm{O}-\mathrm{H}$ stretching vibration, $3323.35 \mathrm{~cm}^{-1}$ for the aromatic group, $2937 \mathrm{~cm}^{-1}$ for alkyl groups, $1870.95 \mathrm{~cm}^{-1}$ for carboxyl group stretching vibration. Medium peaks for amide $C=O$ stretching at $1680 \mathrm{~cm}^{-1}$, and $C=C$ at $1492.9 \mathrm{~cm}^{-1}$ in the aromatic ring were observed in the drug methotrexate. The amine group shows its presence at $952.84-1224.8 \mathrm{~cm}^{-1}$. C-C stretching is present at $817.82 \mathrm{~cm}^{-1}[28,29]$. 


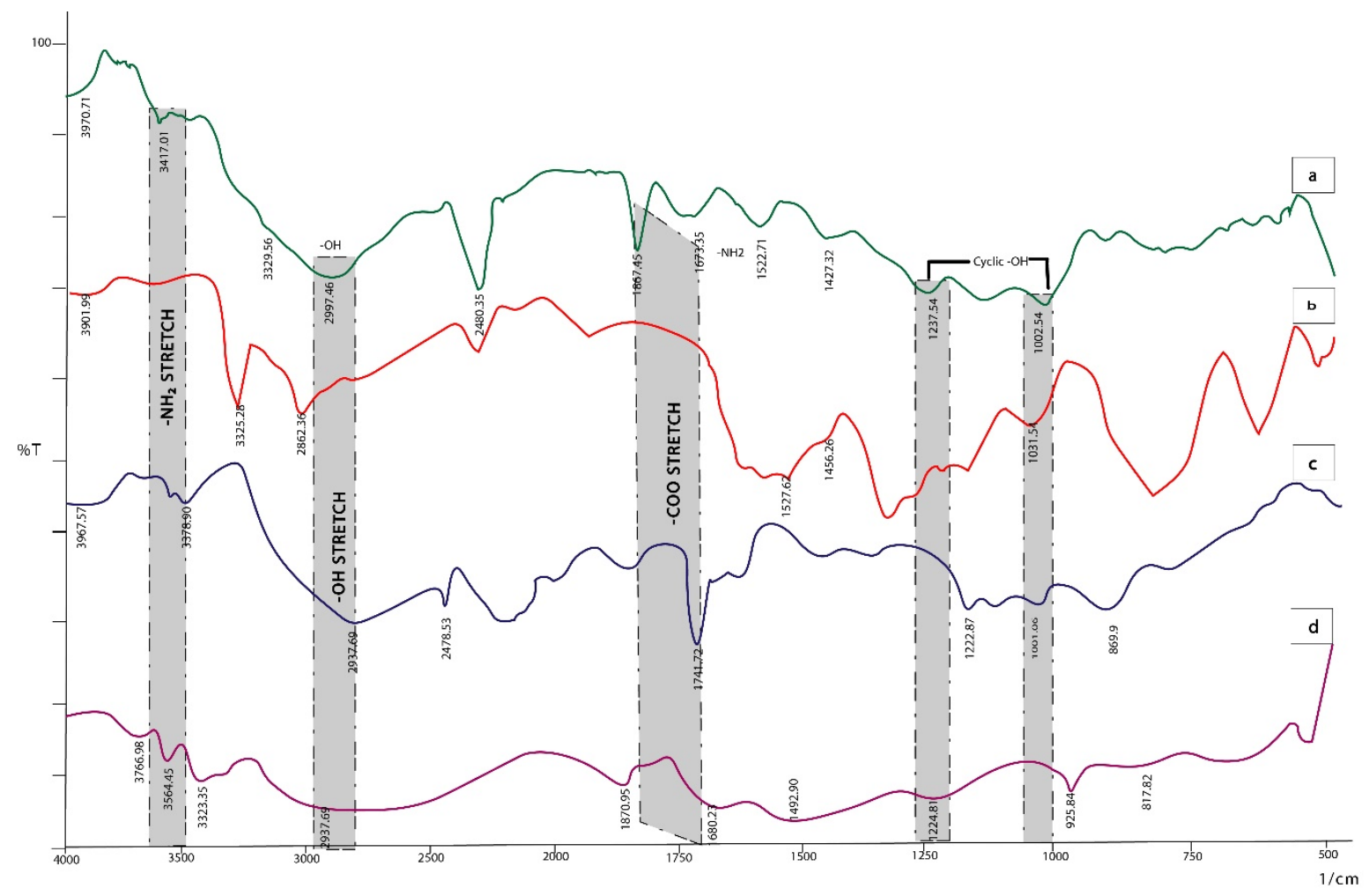

Figure 2. Drug polymer compatibility FTIR studies (a): MTX loaded AEM-CS NPs, (b): CS, (c): AEM and (d): MTX.

The spectrum of CS (Figure 2b) shows character peaks at $3325.28 \mathrm{~cm}^{-1}$ and $2862.36 \mathrm{~cm}^{-1}$ which represent the $-\mathrm{OH}$ and $-\mathrm{CH} 2$ groups, respectively. The peaks at 1527.62 and $1456.26 \mathrm{~cm}^{-1}$ show the NH- bending vibration and the - $\mathrm{OH}$ group of primary alcohol. The peak at 1031.92 represents C-O stretching [30].

The AEM spectrum (Figure 2c) shows peaks at 3378.90 and $2937.69 \mathrm{~cm}^{-1}$ of stretching vibration of $\mathrm{NH} 2$ and $\mathrm{OH}$. The presence of $-\mathrm{OH}$ represents the hydrophilic character of polymer. The band at $2478.53 \mathrm{~cm}^{-1}$ is due to the $\mathrm{CH}$ stretch of $-\mathrm{CH}_{3}$. The peak at $1741.72 \mathrm{~cm}^{-1}$ is a $\mathrm{C}=\mathrm{O}$ stretch that can be found in galacturonic acid; $1222.8-869.9 \mathrm{~cm}^{-1}$ was the fingerprint region of carbohydrates [31].

The IR spectra of MTX loaded AEM-CS NPs in Figure 2a show a shift in the COO-peak shift to $1867.45 \mathrm{~cm}^{-1}$, which is indicative of electrostatic bond formation between two AEM and CS. The bands at 3417.01 and $2997.46 \mathrm{~cm}^{-1}$ are representative of $-\mathrm{NH} 2$ and hydrogen bonded -OH present in CS too. Additionally, the characteristic peaks for cyclic alcohols can be seen in the regions of $1200-1000 \mathrm{~cm}^{-1}$, and are visible in the spectra of polymers too. The spectra indicated that no interaction occurs between the functionalities of the physical mixture of MTX, AEM and CS.

\subsection{Entrapment Efficiency}

The \% entrapment efficiency (\% EE) of MTX-loaded AEM-CS NPs formulations was found to be in the range from $42.08 \pm 1.2$ to $72.23 \pm 2.0$. The $\%$ EE was observed to be decreasing with an increase in either of the polymer's concentrations. This is mainly due to the formation of a loose polymeric network when either of polymer concentrations is increased leading to drug leaching from the matrix, the same results have been observed by studies carried out by Kajjari et al., whilst working on chitosan-guar gum NPs for ciprofloxacin release [32]. The highest \% EE was observed in formulation F2 (1:1) due to adequate interactions between AEM and CS, causing the formation of a compact polymeric matrix which in turn caused a surge in the drug entrapment efficiency of NPs (Table 1). 
Table 1. $\%$ Encapsulation efficiency ( $\% E E)$ of MTX loaded AEM-CS NPs in mean \pm standard deviation (S.D.) $/ n=3$.

\begin{tabular}{cccc}
\hline Formulation & AEM $(w / v \%)$ & CS $(w / v \%)$ & \%Encapsulation Efficiency \\
\hline F1 & 0.02 & 0.01 & $42.1 \pm 1.2$ \\
\hline F2 & 0.01 & 0.01 & $72.2 \pm 2.0$ \\
\hline F3 & 0.01 & 0.02 & $53.4 \pm 2.1$ \\
\hline
\end{tabular}

\section{3. \% Drug Content and Percent Yield}

The \% drug content of MTX-loaded AEM-CS NPs was found to be in the range of $81.2 \pm 1.2$ to $94.5 \pm 1.6$ (Table 2 ). It was observed that the formulation with a 1:1 AEM-CS ratio, i.e., F2 showed an increase in \% drug content. However, in F1 and F3 with AEM-CS ratios of 2:1 and 1:2, respectively, the drug content was decreased. This is due to an increase in size which causes the surface area of NPs to be decreased, leading to drug content lowering. The \% yield was found to be improved, ranging from $50 \pm 1.2$ to $84.3 \pm 0.8$ with an increase in polymer ratios. The increase in yield is due to an increase in the NPs weight owing to the increase in concentrations of AEM and CS, though the increase was more pronounced in F3, with an AEM-CS ratio of 2:1, which is in accordance with previously published research $[33,34]$.

Table 2. Drug content and percent yield of MTX loaded AEM-CS NPs in mean \pm S.D. $(n=3)$.

\begin{tabular}{ccc}
\hline Formulation & \% Drug Content & \% Yield \\
\hline F1 & $84 \pm 1.3$ & $75.7 \pm 1.3$ \\
\hline F2 & $94.5 \pm 1.6$ & $50 \pm 1.2$ \\
\hline F3 & $81.2 \pm 1.2$ & $84.3 \pm 0.8$ \\
\hline
\end{tabular}

\subsection{Particle Size Distribution, Zeta Potential and Morphology of AEM-CS Nanoparticles}

The size distribution and $\zeta$-potential values of AEM-CS nanoparticles are described in Table 3. Dynamic light scattering technique is used to determine the size distribution profile of nanoparticles [35]. Results revealed that the average hydrodynamic diameter of nanoparticles formulations was in the range of 211-269 $\mathrm{nm}$ with an acceptable PDI range of 0.279-0.485. Particle size was smallest when the AEM-CS ratio was 1:1 (Figure 3A). The polydispersity index (PDI) is a dimensionless parameter that tells us the heterogeneity in the dispersion of detected particle size. PDI values less than 0.1 are considered as "Monodisperse" and PDI values greater than 0.7 are considered as "Polydisperse" [36]. PDI results were calculated by data obtained from DLS analysis. Particle size was smallest when the AEM-CS ratio was 1:1 (Figure 3A,C). Changes in the mass ratio of CS and AEM resulted in a shift in particle size. An increase in either CS or AEM leads to bigger particle size. These findings indicated that the AEM-CS ratio affects the particle size [35].

Table 3. Characterization of MTX loaded AEM-CS NPs.

\begin{tabular}{ccccc}
\hline Sample & $\begin{array}{c}\text { AEM: CS } \\
\text { (Mass Ratio) }\end{array}$ & $\begin{array}{c}\text { Z-Average } \\
(\mathbf{n m})\end{array}$ & $\begin{array}{c}\text { Polydispersity } \\
\text { Index }\end{array}$ & $\begin{array}{c}\zeta \text {-Potential } \\
\text { (mV) }\end{array}$ \\
\hline F1 & $2: 1$ & 238.4 & 0.485 & -9.1 \\
F2 & $1: 1$ & 213.8 & 0.279 & +11.4 \\
F3 & $1: 2$ & 254.2 & 0.361 & +22.7 \\
\hline
\end{tabular}

Pure chitosan is a cationic polysaccharide due to the presence of free amino groups, whereas pure AEM is anionic because of free carboxylic groups [37,38]. These groups are responsible for the net positive or negative charge of polymers and influence $\zeta$-potential values. Correspondingly, for nanoparticles prepared with equal mass ratios of CS and AEM, 
the $\zeta$-potential of nanoparticles was $+11.4 \mathrm{mV}$. An increase in $\zeta$-potential value was observed when CS mass ratio was increased. On the other hand, $\zeta$-potential was reduced upon increasing the ratio of AEM in composition. $\zeta$-potential values of nanoparticles prepared with different AEM-CS ratios are shown in Figure 3B. In Figure 3C, the SEM images along with their respective histogram representing the size distribution of nanoparticles formulations (F1-F3) of three different ratios were presented, which revealed that all nanoparticles had solid, smooth, and spherical shapes. By applying the Gaussian fit of counts on distribution frequency, the mean size distribution was in accordance with DLS analysis. DLS analysis only talks about size distribution but the exact shape of nanoparticles accessed with SEM analysis and more even size has been clearly seen at a ratio of 1:1 in Figure 3C.

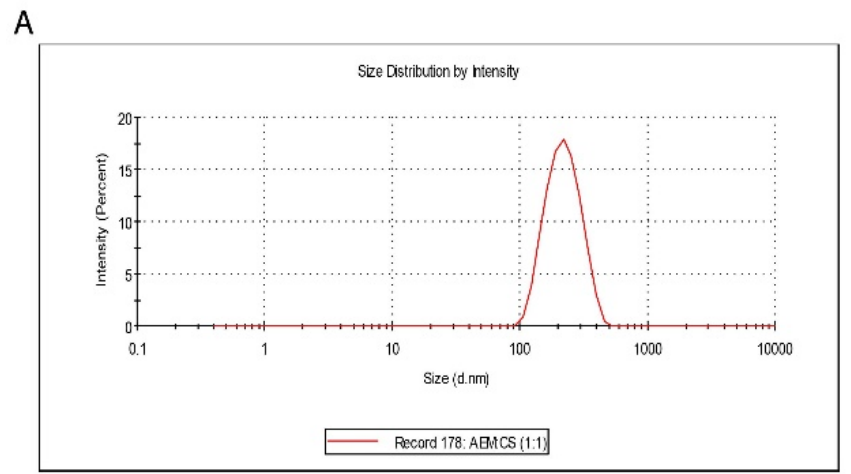

B

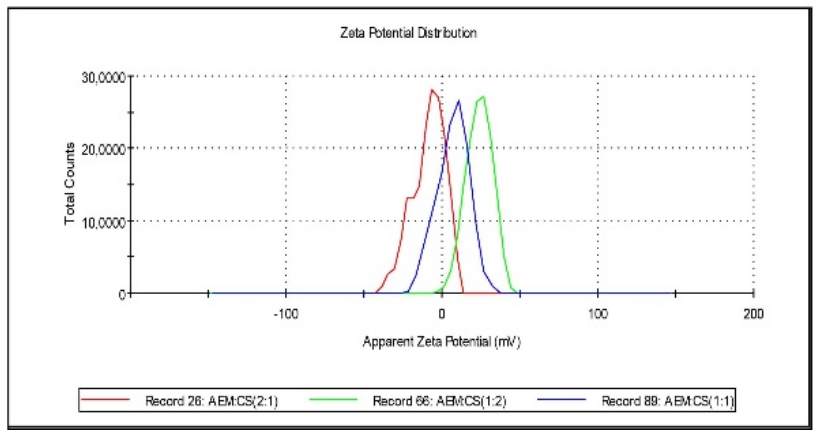

C
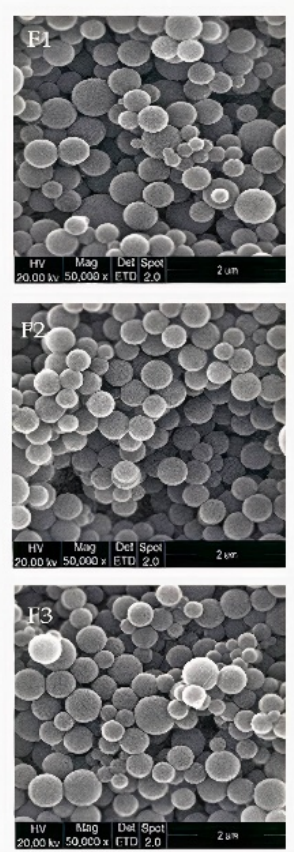

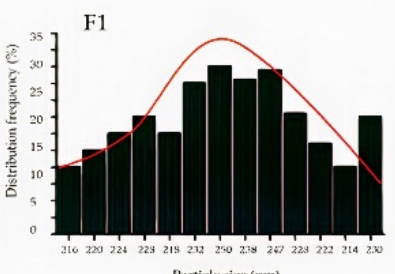

Particle size (num)
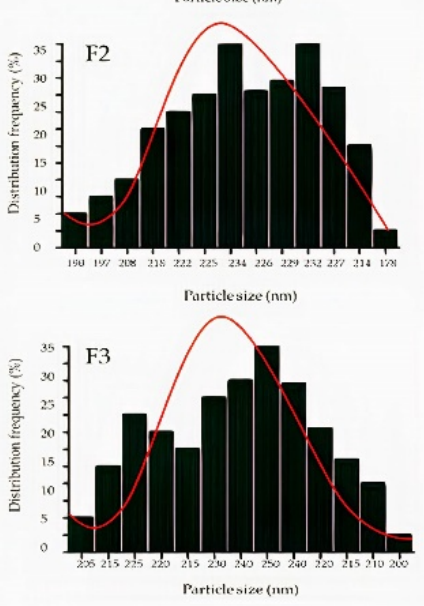

Figure 3. (A) Z-average d. nm AEM:CS at 1:1 ratio. (B) Zeta-potential (mV) of AEM:CS at the ratios of (2:1, 1:1 and 1:2). (C) SEM images along with their respective size distribution histograms of AEM:CS at the ratios of $(2: 1,1: 1$ and $1: 2)$.

\subsection{In-Vitro Drug Release Studies}

A tumor targetted drug delivery system requires the exhibition of little or no drug release before its site of action (cancerous cells). If not, then the drug will be absorbed in the gastrointestinal tract (GIT) causing a decrease in the efficacy of the drug. Additionally, the sustained and controlled delivery of hydrophobic drugs is preferred as it reduces the need for frequent drug administration, besides decreasing several side effects $[39,40]$.

The MTX cumulative release from AEM-CS nanoparticles in simulated normal and cancerous cells conditions was studied, to determine the $\mathrm{pH}$ responsiveness of formulated NPs towards the cancerous microenvironment (Figure 4). The release profiles in simulated gastric fluid (SGF; $\mathrm{pH}$ 1.2) for the first $2 \mathrm{~h}$ and later in simulated intestinal fluid (SIF; $\mathrm{pH} 7.4$ ) for $30 \mathrm{~h}$ were carried out. This was performed to mimic the $\mathrm{pH}$ and transit time of the gastrointestinal tract (GIT). At pH 1.2, all formulations (F1, F2, F3) showed an insignificant MTX release in between $12.13-14.01 \%$ range while at $\mathrm{pH} 7.4$ CDR of $41.62-53.4 \%$ was observed, respectively. The quantity of drug discharge was increased with an increase in polymer ratio because of the enhancement in the diameter of the polymeric membrane 
and poor interaction between polymers which surged the diffusion rate of the drug in GIT mimicking media $[32,41]$.
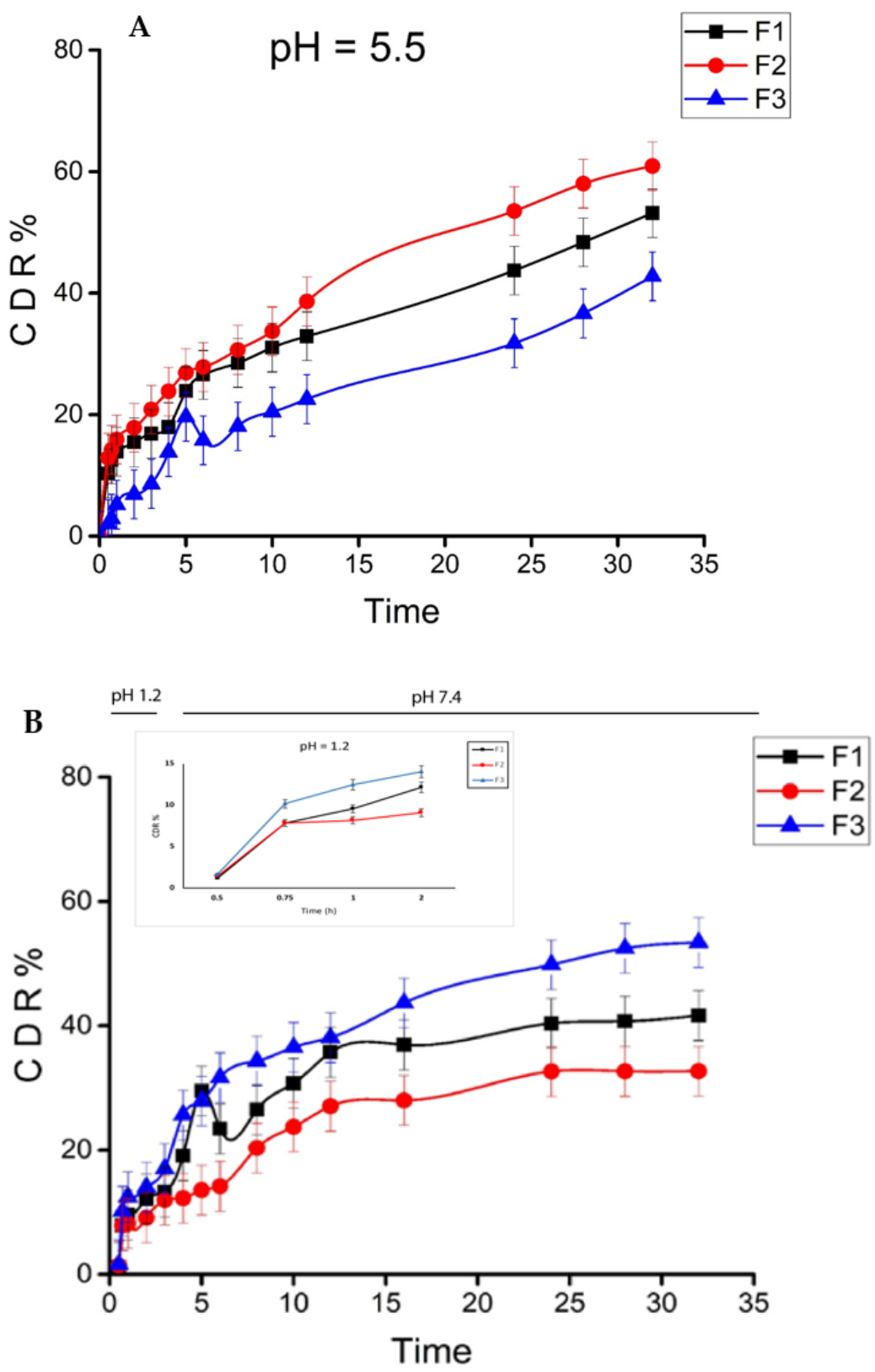

Figure 4. In vitro cumulative drug release percentage (CDR \%) of MTX loaded AEM-CS nanoparticles. (A) $\mathrm{pH} 5.5,(\mathbf{B}) 1.2$ and 7.4 at $37^{\circ} \mathrm{C} .(n=3 /$ Mean \pm S.D. $)$.

At $\mathrm{pH} 5.5$, the release rates of formulation (F1, F2, F3) showed an escalated rate of $53.17 \%, 60.91 \%$ and $42.76 \%$, respectively. The drug was released more quickly at pH 5.5 due to the protonation of carboxyl and amino groups present on the AEM-CS surface which increased the swelling potential of both polymers (AEM and CS) in a slightly acidic medium. This is due to the repulsion between similar charges that allowed faster drug release in $\mathrm{pH} 5.5$ [42]. In contrast, the release is slow in $\mathrm{pH} 1.2$ and 7.4 as the swelling index is low. The results were consistent with other previous studies carried out on the $\mathrm{pH}$-responsive nanocarriers of MTX though unlike our NPs most of these require a hectic synthesis procedure [42-44].

The F2 nanoparticles, which contain $0.01 w / v \%$ AEM and $0.01 w / v \%$, exhibited better sustained drug release compared to other formulations, showing a more sensitive and 
efficient drug release at $\mathrm{pH} 5.5$ and slow sustained release at $\mathrm{pH} 1.2$ and 7.4, indicating nanoparticles sensitivity to tumor $\mathrm{pH}$ [45]. This efficient MTX release at acidic tumor $\mathrm{pH}$ from spherical AEM-CS NPs prevents the loss of drug in the vicinity of normal cells with improved endosomal MTX uptake [46]. The results advocate the value of these tumor $\mathrm{pH}$-responsive nanoparticles as effective means to release chemotherapeutics in the tumor environment reducing the damage to normal tissues.

\subsection{Drug Release Kinetics}

To investigate the MTX release kinetics from AEM-CS nanoparticles, results from five mathematical models were analyzed. The selection of kinetic model was based on $R^{2}$ obtained close to unity. Table 4 shows MTX release kinetic constant $(\mathrm{k})$ and correlation coefficient $\left(\mathrm{R}^{2}\right)$. At all $\mathrm{pH}$ values, i.e., 1.2, 5.5 and $\mathrm{pH}$ 7.4, the nanoparticles showed a good fit to the Higuchi model. The Higuchi model has also been used in multiple published studies to investigate anticancer drug release from biopolymer-based carriers [47,48]. This model comprises three suppositions. Initially, the drug content is higher than drug solubility potential, accompanied by the fact that particle size is less than matrix thickness with no drug particle on the surface. Lastly, the diffusion of the drug is constant and mainly occurs via pores hydrophilic polymeric matrix solubilizes easily on contact with solvents [49].

Table 4. (a): Modelling and release kinetics of nanoparticles at pH 5.5. (b): Modelling and release kinetics of nanoparticles at $\mathrm{pH} 7.4$.

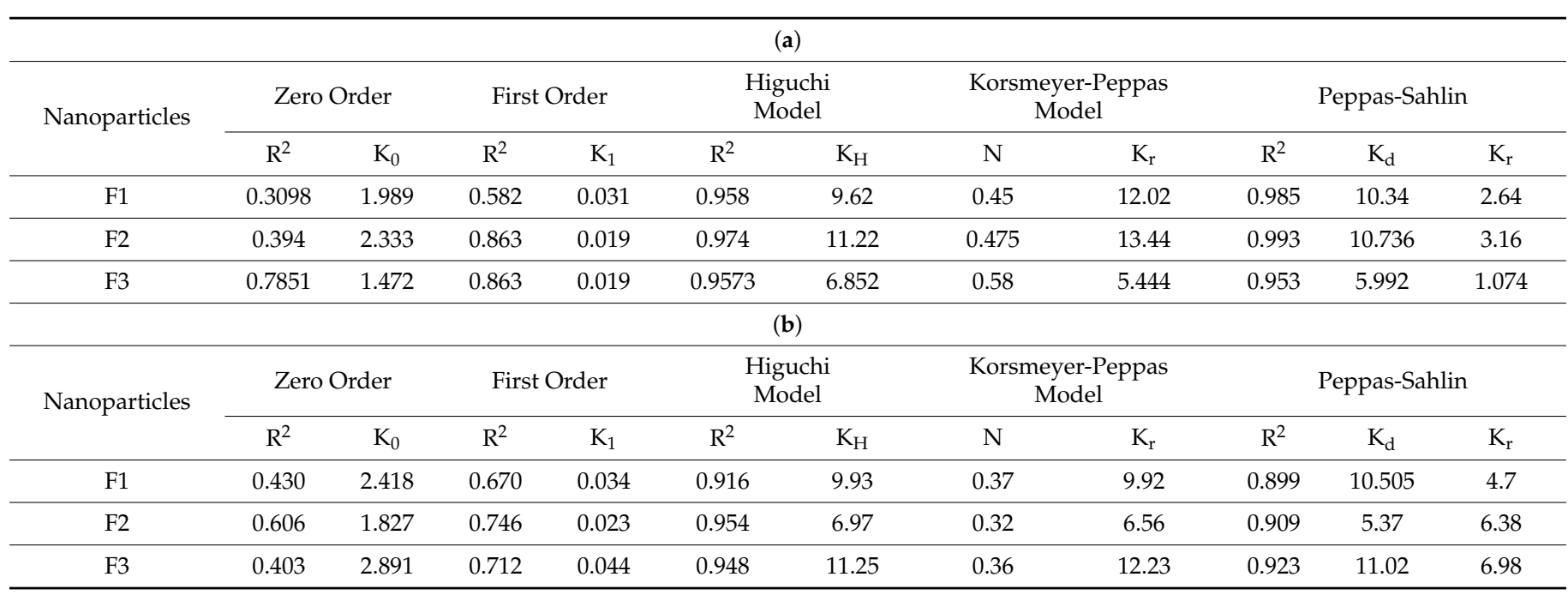

The data was further fitted to Korsmeyer Peppas and Peppas-Sahlin model to understand the release mechanism. The said models indicated that the drug release was driven by diffusion and polymer chain relaxation in the case of $\mathrm{pH}$ 5.5. In this scenario, the diffusion dominates in accord with $K_{d}$ and $K_{r}$ values as the $K_{d} / K_{r}$ ratio is $>1$. The " $n$ " values range between 0.43 and 0 . indicates an anomalous diffusion drug release too (Table 4a) [50].

The kinetic release results at $\mathrm{pH} 1.2$ and 7.4 showed that the diffusion phenomenon was mainly followed during the drug release. The low $n$ values, i.e., $<0.45$ calculated by the Korsmeyer Peppas model and $\mathrm{K}_{\mathrm{d}} / \mathrm{K}_{\mathrm{r}}$ in Peppas-Sahlin affirmed the mediation of drug release by diffusion which is in agreement with published literature (Table $4 b$ ) [50-52].

\subsection{In-Vivo Acute Toxicity of AEM-CS Based Blank Nanoparticles}

Acute toxicity is used to assess the toxicity of drug delivery devices and their lethal dosage (LD50) values. Furthermore, the use of relevant species of animals for in-vivo toxicity analysis has a principal role in evaluating the long-term toxicity data. These studies can ultimately be translated into accessing the human tissue's reactivity profile [53,54]. In 
the present study, neither any toxic effects (skin color alteration, tremors, and diarrhea) nor mortality were observed. Moreover, the behavioral and sleep patterns remained the same, and no mortality was observed in mice for a time duration of 14 days. No significant body weight change was observed on either of the groups for 14 days and since no animal died, the lethal dosage could not be measured. The food and water consumption were the same in both groups, though a slight weight decrease was observed in the test group. However, this weight change was not different when compared to control group animals (Figure 5a).

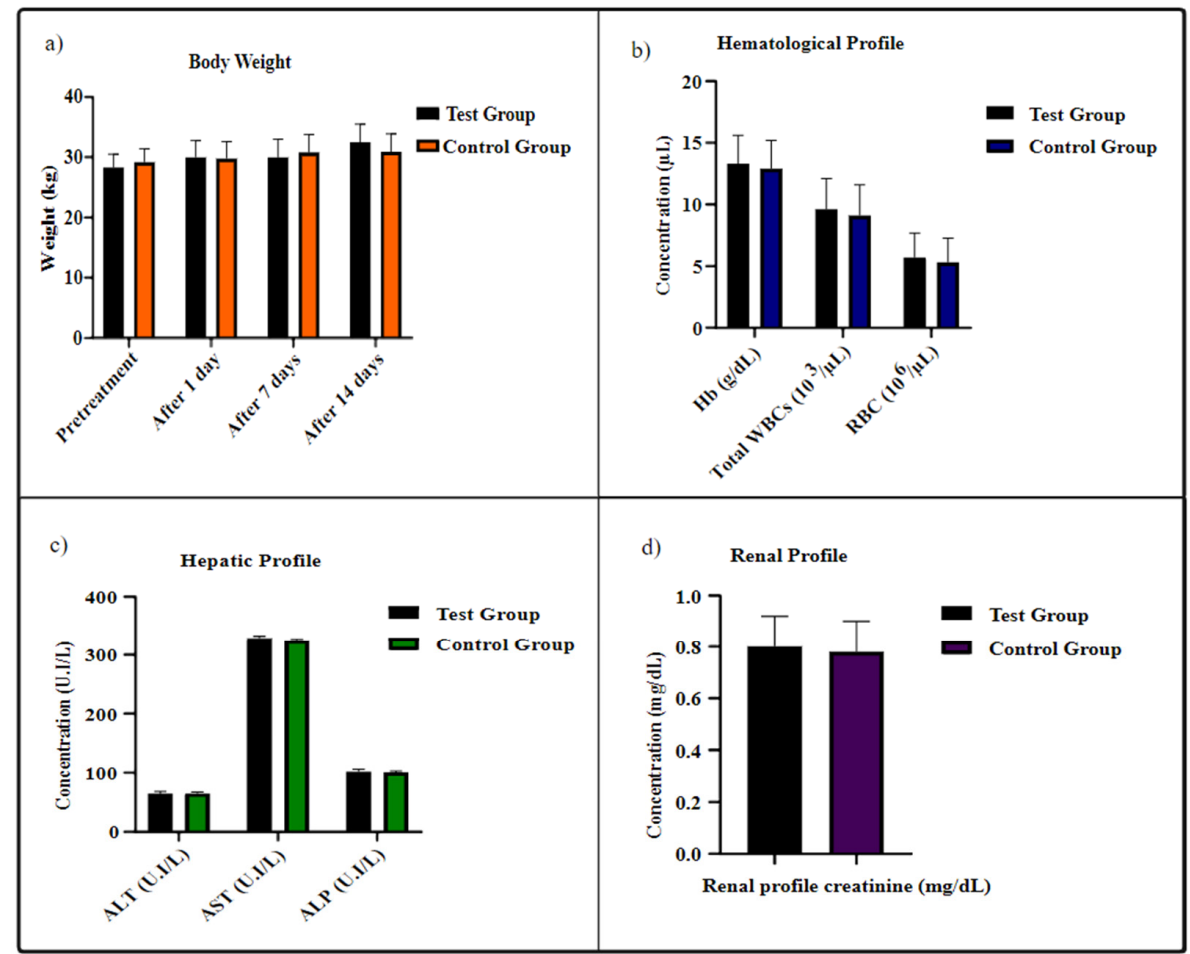

Figure 5. Biochemical profile of albino mice after repeated dose administration over a time duration of 14 days (a) body weight, (b) hematological profile, (c) hepatic profile, (d) renal profile Results are represented as mean \pm S.D. with $n=7$ and $p<0.05$.

\subsection{Blood and Hematological Analysis}

Furthermore, hematological and biochemical profiles were assessed (Figure 5), as these parameters facilitated estimating the influence of the drug-delivery system on blood composition. The results depicted no substantial alteration in hematological and biochemical profiles of the tested group in comparison to the control one.

Furthermore, the liver and kidneys are the main sites for biological parameters fluctuations and damage to such organs, is most likely to increase the hepatic enzymes (ALT, AST and ALP) and renal creatinine. The analysis of these hepatic and renal parameters demonstrated the AEM and CS constituted NPs to be non-toxic and safe. Besides that, no inflammation and degeneration in the liver and kidneys of mice were observed, prompting the use of the AEM-CS NPs based drug carriers as chemotherapeutics delivery modules $[55,56]$.

\subsection{Cytotoxicity Analysis}

The in vitro cytotoxic activity of MTX loaded NPs (F2) on normal cells (Vero cell lines) and cancer cell lines (MCF-7 and MDA-MB231) was investigated by MTT assay. The cell viability was significantly high for Vero cells on treatment with blank AEM-CS NPs, showing their non-toxicity towards these cells and significant biocompatibility.

Formulation F2, with an AEM and CS ratio of 1:1, was selected as a potential candidate for this study as it has the smallest size and the highest drug load amongst all 
three formulations. Additionally, the blood capillaries are of diameter 5-6 um, so the administration of smaller sized NPs can help in the prevention of embolism and capillaries blockage. Vero cells were less sensitive towards the anti-proliferating and toxic activity of MTX loaded AEM-CS NPs. Therefore, even after an incubation time duration of $48 \mathrm{~h}$ MTX and MTX loaded AEM-CS NPs did not substantially cause cell death, i.e., cell viabilities with minimalistic values of $75 \%$ and $78.02 \%$, respectively.

The MTX and MTX loaded AEM-CS NPs (Figure 6B) significantly inhibited cell proliferation in both MCF-7 and MDA-MB231 cancer cells after $48 \mathrm{~h}$, whereas there were no significant cytotoxic effects on cell viability in the case of the Vero cell line [56]. We observed a high time and concentration dependent activity in MTX loaded AEM-CS NPs in comparison to free MTX in concentrations of 3.12-200 $\mu \mathrm{g} / \mathrm{mL}$, It was observed that in the initial $24 \mathrm{~h}$ the MTX loaded AEM-CS NPs displayed a slightly higher \% cell viability ratio than free MTX (Figure 6A). This can be evidenced by the fact that free drug is rapidly taken up by cancerous cells via passive diffusion due to the cell's immediate exposure to whole drug concentration whereas only a portion of the drug is exposed to cell lines in NPs [57]. The drug is expected to gradually increase till it attains a steady state in the NPs. Therefore, after $48 \mathrm{~h}$, a remarked high cellular cytotoxicity for both cell lines was observed by MTX loaded NPs [58,59]. The anticancer efficacy, however, was significant when compared with several previously reported nanocarriers for MTX. However, further in-vivo studies are required for the complete characterization of anticancer efficacy of MTX loaded AEM-CS NPs.

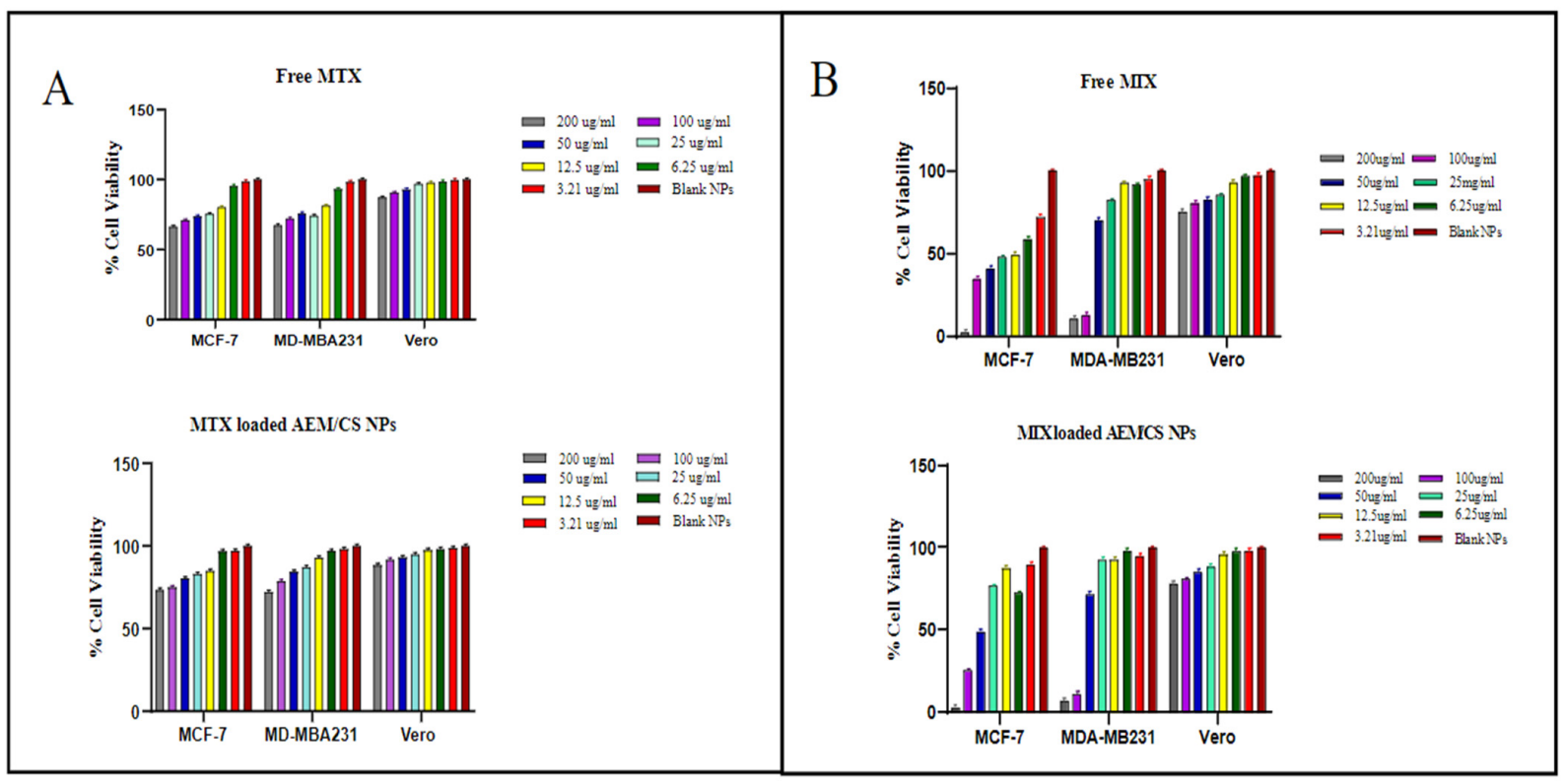

C

MITX loaded AEMI-CS NPs

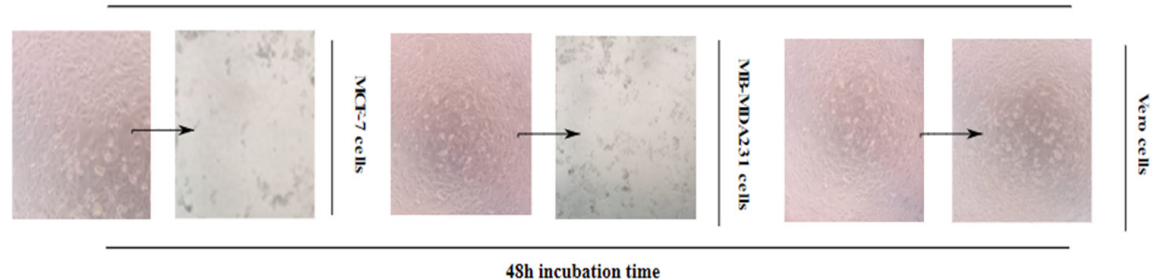

Figure 6. Quantitative cytotoxicity analysis of free MTX and MTX loaded AE/CS NPs (F2) on MCF-7, MDA-MB231 cancer cells and Vero (normal cells) after (A) $24 \mathrm{~h}$, (B) $48 \mathrm{~h}$ treatment duration with DMSO and Blank AEM-CS NPs (no drug) as control, (C) Representative images of MCF-7, MDAMB231 cancer cells and Vero (normal cells) upon treatment with F2 formulation (Scale bar $=1 \mathrm{~mm}$ ). Data are presented as Mean \pm S.D; $p<0.001$. 


\subsection{Stability Studies}

The particle size and entrapment efficiency of MTX-loaded NPs were determined initially and later weekly till 21 days, shown in Figure 7. The data showed no potential difference in the size of nanoparticles and encapsulation efficiency of formulation (F2), depicting the NPs encapsulation layer stability.

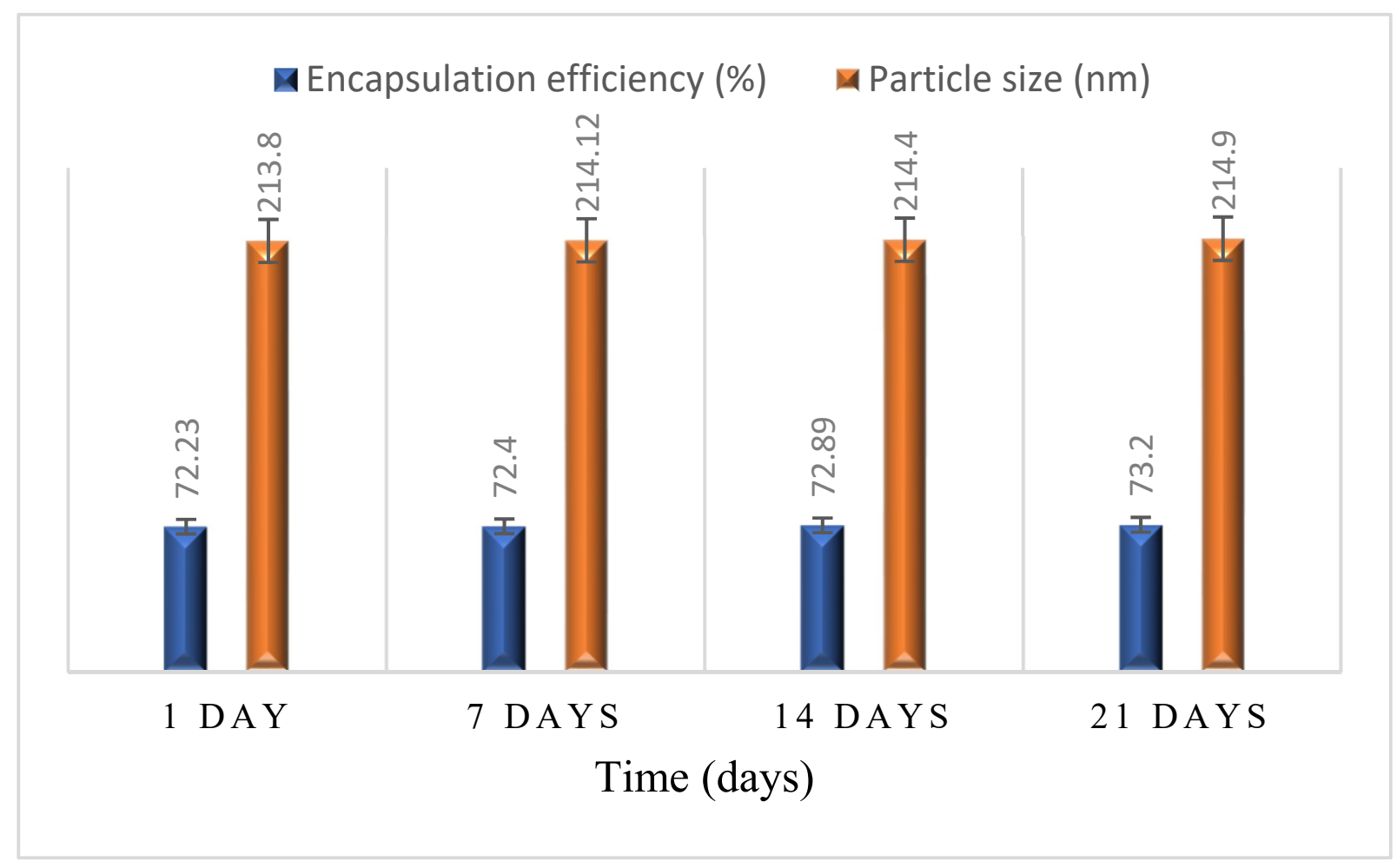

Figure 7. Stability studies of MTX loaded AEM/CS NPs over a time duration of 21 days in mean \pm S.D $(n=3)$.

\section{Material and Methods}

\subsection{Material}

Chitosan (medium molecular weight, $75-85 \%$ de-acylated) was purchased from Sigma Aldrich. Methotrexate was received as a gift from the pharmaceutical company of Peshawar. Ethanol, sodium hydroxide, glacial acetic acid $>99.7 \%$, and other chemicals and reagents used in the present study were obtained from Sigma-Aldrich (GmBh chemie, Schnelldorf, Germany) and Fisher Scientific, UK. All solutions preparation was made by using ultrapure water and all chemicals utilized were of analytical grade.

\subsection{Mucilage Extraction}

Fresh Okra pods were purchased from the local market, Sargodha, Punjab, Pakistan. The authentication of the plant was performed at the Department of Botany, University of Sargodha, Sargodha. Mucilage extraction was performed by following reported methods by Baveja and Wahi $[60,61]$. Fresh pods were washed and cut into small pieces. The mucilage precipitation was carried out by ethanol in water in ratio 3:1. Once separated, the mucilage was oven-dried at $40{ }^{\circ} \mathrm{C}$ and passed through sieve $\# 80$ and stored in airtight vials for future study. Mucilage suspension was prepared by adding it into deionized water followed by centrifugation for $20 \mathrm{~min}$ at $3000 \mathrm{rpm}$ at room temperature. The supernatant was evaporated, and mucilage was obtained as the pellet was freeze-dried, and stored in a plastic air-tight container. 


\subsection{Formulation of Nanoparticles}

Methotrexate nanoparticles were prepared with the help of an earlier reported coacervation method with slight modifications followed by ultra-sonification [62,63]. A solution of AEM $(0.02 \% w / v)$ in distilled water was prepared under constant stirring with a $\mathrm{pH}$ adjustment of 5.2 by $0.1 \mathrm{~N} \mathrm{HCl}$. Whereas the preparation of $\mathrm{CS}(0.02 \% w / v)$ was performed in $0.1 \%$ acetic acid under magnetic stirring. The $\mathrm{pH}$ of the CS solution was adjusted to 5.5 by using $5.51 \mathrm{~N} \mathrm{NaOH}$.

AEM solution was added to the CS solution with a stirring duration of $20 \mathrm{~min}$ at $40^{\circ} \mathrm{C}$. MTX solution $(1 \mu \mathrm{g} /) \mathrm{mL}$ was prepared by using dimethyl sulfoxide (DMSO). For this, $10 \mathrm{mg}$ of MTX was dissolved in $10 \mathrm{~mL}$ of DMSO and serially diluted further to obtain a solution of $1 \mu \mathrm{g} / \mathrm{mL}$ concentration. Three formulations were prepared in a similar way altering the polymers (CS and AEM) ratios as 2:1, 1:1, 1:2 while keeping the drug (MTX) concentration constant $(1 \mu \mathrm{g} / \mathrm{mL})$. The samples obtained in the result were centrifuged at $12,000 \mathrm{rpm}$ at $40{ }^{\circ} \mathrm{C}$ for $45 \mathrm{~min}$. The NPs obtained in form of coacervate were lyophilized and stored.

\subsection{Fourier Transform Infrared (FTIR) Spectroscopy}

Spectral investigations of AEM-CS nanoparticles, native polymer (AEM and CS) and drug (MTX) were recorded in the region $4000-400 \mathrm{~cm}^{-1}$ by IR Prestige-21 spectrophotometer (Shimadzu, Kyoto, Japan). This analysis was made for the identification of any interaction between polymers and drugs $[64,65]$.

\subsection{Nanoparticles Evaluation \\ 3.5.1. Dynamic Light Scattering (DLS) Analysis}

The particle size, polydispersity index (PDI) and zeta potential evaluation of MTXAEM-CS NPs, with $1 \mathrm{mg} / \mathrm{mL}$ concentration, was performed by a Zetasizer Nano ZS (Malvern Instruments, Malvern, UK) at room temperature [66]. For this investigation, dilute solutions were employed, as concentrated ones lead to false measurements. The inaccuracy in particle size study in concentrated solutions is mainly owed to the multiple scattering [67]. Cumulants method of analysis was used in Malvern software to analyze the data. With appropriate refractive indices for the bulk suspension droplet, this software considered each particle as a sphere and considered that in bulk distribution. To avoid the tendency of particle aggregation, a $0.2 \mu \mathrm{m}$ syringe filter was used to add the samples. Each formulation was analyzed thrice and the collected results were averaged. Data obtained from the same software was also used for the analysis polydispersity index [68]. Polydispersity index is calculated by dividing the square of standard deviation with average particle diameter by Equation (1).

$$
\text { PDI }=\left(\sigma^{2} / d\right)
$$

\subsubsection{Morphological Analysis}

The analysis of morphology and surface of optimized MTX loaded AEM-CS NPs was made by FEG-SEM EM8100F (Field Emission Gun Scanning Electron Microscope equipped with EDX Analyzer) with an accelerating voltage of $20 \mathrm{kV}$. Image J software was used for the analysis of SEM micrographs. The samples were placed on double-sided tape secured on aluminum stubs and scanned at $15 \mathrm{KV}$ after gold coating $[68,69]$. The micrographs were acquired after adding one drop of NPs suspension over copper grid accompanied with negative attaining by uranyl acetate at $60 \mathrm{kV}$ accelerating voltage [58].

\subsubsection{Encapsulation Efficiency}

For the determination of encapsulation efficiency (EE), all the formulations were suspended in water; $0.5 \mathrm{~mL}$ and DMSO; $0.9 \mathrm{~mL}$ based binary mixture. The suspensions were centrifuged at $14,000 \mathrm{rpm}$ for $5 \mathrm{~min}$ at $4{ }^{\circ} \mathrm{C}$ in a centrifuge machine to assess the MTX amount. The supernatant obtained was filtered by Whatman filter paper and the amount of 
un-incorporated MTX was quantified from the absorbance in UV-spectrophotometer from Shimadzu (Kyoto, Japan) in a scanning range of 200-400 nm [65,70].

The EE of polymers in formulations was calculated by means of the calibration curve of standard MTX solutions $(10,20,40,60,80,100 \mu \mathrm{g} / \mathrm{mL}$ ) at $303 \mathrm{~nm}$ by Equation (2).

$$
\text { Encapsulation efficiency }=\frac{\text { Amount of total drug }- \text { Amount of free drug }}{\text { Amount of total drug added }} \times 100
$$

\subsubsection{Percentage Yield and Drug Content}

For percentage drug content, $5 \mathrm{mg}$ of MTX loaded AEM-CS NPs were suspended in water $(0.5 \mathrm{~mL})$ followed by the addition of DMSO $(9.5 \mathrm{~mL})$. The nanoparticle suspensions were centrifuged at $12,000 \mathrm{rpm}$ for $45 \mathrm{~min}$ under the cooling environment same as in the refrigerator $\left(5^{\circ} \mathrm{C}\right)$. The supernatant was collected, and the NP pellets were dried up. The concentration of MTX was determined by UV-Spectrophotometer (Shimadzu, Kyoto, Japan). An equal amount of AEM-CS blank NPs was also used as blank (Equation (3)). For calculation of \% yield equations 4 , the weights of nanoparticles, pure drug and polymers were also determined $[65,71]$.

$$
\begin{gathered}
\% \text { Drug content }=\frac{\text { Weight of drug in nanoparticles }}{\text { Weight of nanoparticles recovered }} \times 100 \\
\% \text { Yield }=\frac{\text { Weight of nanoparticles recovered }}{\text { Weight of total solid }(\mathrm{AE}+\mathrm{CS}+\mathrm{MTX})} \times 100
\end{gathered}
$$

\subsubsection{In-Vitro Drug Release}

The in-vitro MTX release was determined by the dialysis sac method via dissolution rate apparatus, USP type-II (PTD7, Pharma-Test, Hainburg, Germany). A $3 \mathrm{~mL}$ sample of NPs was placed in a dialysis sac (cut off $10,000 \mathrm{kDa}$ ) and secured to paddle with a release medium of $200 \mathrm{~mL}$ of phosphate buffer at $\mathrm{pH} 1.2$ for an initial $2 \mathrm{~h}$ which was later replaced by alkaline phosphate buffer solution (PBS) of $\mathrm{pH} 7.4$ with constant stirring at $25 \mathrm{rpm}$ at $37 \pm 0.5^{\circ} \mathrm{C}$. The procedure was repeated for all formulations at $\mathrm{pH} 5.5$ so as to study the release rates in the tumor microenvironment. A $3 \mathrm{~mL}$ sample was withdrawn from cells at $30,45,1,2,3,4,5,6,8,10,12,24,28$ and $32 \mathrm{~h}$, respectively whilst replacing it with an equivalent volume of PBS. The absorbance of withdrawn samples was noted with UV-spectrophotometer at $303 \mathrm{~nm}$. The concentration at a given time $(t)$ was obtained by the calibration curve of MTX. The standard calibration curve of methotrexate in PBS $(1,2,3,4,6,8,10,15,20,25,30 \mu \mathrm{g} /) \mathrm{mL}$ was obtained and release was determined by Equation (5) [45,72].

$$
\text { Drug release } \%=\frac{\text { Amount of MXT released }}{\text { Amount of loaded MTX }} \times 100
$$

\subsubsection{Kinetic Studies of Drug Release}

The dissolution profiling of MTX loaded AEM-CS NPs was carried out by kinetic models to ensure that the drug dissolution from nanoparticles was occurring in an appropriate manner [70], as follows:

Zero Order model: The initial use of this model was mainly to describe the MTX-loaded AEM-CS NPs at a concentration-independent release rate, represented by Equation (6).

$$
Q_{t}=Q_{0}+K_{0} \cdot t
$$

where $Q_{t}=$ amount of drug dissolved at the time ' $t$ '; $Q_{0}=$ Initial drug amount in solution. 
First Order model: The model explored the release of hydrophilic drugs from a porous matrix in comparison to drug content inside the drug carrier, in accordance with Equation (7).

$$
\log Q_{t}=\log Q_{0}-\frac{K_{1}}{2.303} t
$$

where $Q_{t}=$ amount of drug dissolved at time $\mathrm{t} ; Q_{0}=$ Initial drug amount in solution; $K_{1}=$ first-order rate constant.

Higuchi model: This model was used to describe the cumulative percent release of hydrophilic drugs from hydrophobic polymeric matrixes in relation to the square root of time, represented by Equation (8).

$$
Q_{t}=K_{H} t^{\frac{1}{2}}
$$

$K_{H}=$ Higuchi model constant; $Q_{t}=$ amount of drug dissolved at time ' $t$ '

Korsmeyer-Peppas model: The characterization of the mechanism involved for cumulative drug release incorporated within polymeric matrixes was made by this model, Equation (9).

$$
\frac{M_{t}}{M_{\infty}}=K_{r} t^{n}
$$

$\frac{M_{t}}{M_{\infty}}=$ drug fraction release at time " $t$ "; $K_{r}=$ release constant; $n=$ release mechanism dependent exponent

Peppas-Sahlin model: The extent of drug diffusion accompanied by polymeric matrix relaxation was described by the Peppas-Sahlin kinetic model, expressed by Equation (10):

$$
\frac{M_{t}}{M_{\infty}}=K_{d} t^{0.5}+K_{r} t^{1}
$$

$\frac{M_{t}}{M_{\infty}}=$ Fraction of drug with release time ' $t$ '; $K_{d}=$ rate constant of diffusion; $K_{r}=$ rate constant of relaxation

\subsubsection{In-Vivo Acute Toxicity of AEM-CS Based Blank Nanoparticles}

The acute toxicity of both polymers, i.e., AEM and CS was tested by repeated dose (14 days) technique. All the experimental work was performed in accordance with OECD guidelines and verification was made by the ethics committee of the University of Sargodha (UOS), Sargodha, Pakistan under Ref. No 70B18 IAEC/UOS (PREC). For this, Swiss albino mice weighing $29 \pm 1.2 \mathrm{~g}$ were purchased from Animal Centre, UOS, of either sex and placed in a clean house facility.

Animals were randomly distributed into two groups $(n=5)$ with Group I as control and Group II as a test group. The control group was treated with water and laboratory chow diet whilst the test group was intravenously administrated with an AEM-CS NPs dose of $10 \mathrm{mg} / \mathrm{kg}$ via tail vein for 14 days. A daily observation was made to check the signs of ill health for a time duration of 14 days.

\section{Physical Observations}

A daily observation was made about the health of mice, side effects in response to treatment and changes in the vitals, i.e., skin, eyes, mucosal membranes, behavior, sleep pattern and deaths for a time duration of 14 days. The body weights were also assessed before the treatment and on the 1st, 7th and 14th day after dose administration. All the measurements were compared with the control group.

Biochemical and Hematological Profiling

Bodyweight was measured before treatment and then observations were made on 1st, 7th and 14th along with hematological and biochemical profiling after 14 days. For biochemical and hematological profiling, the mice were anesthetized and blood samples were collected by cardiac puncture. The collected samples were analyzed for Hemoglobin; $\mathrm{Hb}$, WBCs; White blood cells and RBCs; Red Blood cells, the liver enzymes (ALT; Alanine 
Aminotransferase, AST; Aspartate Aminotransferase, ALP; Alkaline Phosphatase) and creatinine were also analyzed according to the International Federation of Clinical Chemistry and Laboratory Medicine (IFCC) primary reference procedures using an Olympus AU2700 Chemistry analyser ${ }^{\circledR}$ (Olympus Optical, Tokyo, Japan) [55].

\subsubsection{Cell Viability Studies}

The cell viability analysis is a key study to comprehend a new drug delivery module and assessment of their biomedical applications. The in-vitro cytotoxicity of optimized nanoparticles formulation (F2) in the MCF-7 and MDA-MB231 cancerous cell lines and Vero cells taken as normal was evaluated by MTT assay. The cell lines were cultured in DMEM (Dulbecco's Modi-field Eagle medium that contained four times higher concentrations of amino acids and vitamins) and $10 \% \mathrm{FBS}$. The cells were seeded at $37{ }^{\circ} \mathrm{C}$ in a $5 \% \mathrm{CO}_{2}$ atmosphere in 96 well plates $\left(1 \times 10^{4}\right.$ cells in each well $)$ and incubated for $48 \mathrm{~h}$. The test samples were solubilized in dimethyl sulfoxide (DMSO) in $500 \mu \mathrm{g} / \mathrm{mL}$ concentration and diluted to $200 \mu \mathrm{g} / \mathrm{mL}$ by water and frozen for later use. The frozen concentration $(200 \mu \mathrm{g} / \mathrm{mL})$ fter being thawed, was diluted in sequential concentrations of nanoparticles $(3.12,6.25,12.5,5,100 \mu \mathrm{g} / \mathrm{mL})$ and incubated for $48 \mathrm{~h}$ with culture plates. The cell lines were also treated with the same concentration of MTX. One hundred microliters of MTT with a concentration of $5 \mathrm{mg} / \mathrm{mL}$ was added to each well, followed by additional $4 \mathrm{~h}$ incubation, with subsequent removal of the culture media with DMSO in each well. The absorbance was read at 570 and $650 \mathrm{~nm}$ via a microplate reader (Thermo Fisher Scientific, Rockfold, IL, USA) [51]. The experiment was conducted in triplicate and results are presented in mean \pm S.D.

$$
\text { Cell viability }=\text { Test cells }(\text { abs }) / \text { Control cells }(\text { abs }) \times 100
$$

\subsubsection{Stability Studies}

The stability of MTX loaded AEM-CS nanoparticles was determined at $25{ }^{\circ} \mathrm{C} \pm 2{ }^{\circ} \mathrm{C}$ by measuring the size and encapsulation efficiency on 1st, 7 th, and 14 th days whilst keeping an eye on the growth of crystals if any [27].

\subsection{Statistical Analysis}

The results were analyzed by one-way ANOVA $p<0.05$ statistically with results taken in triplicate and presented as mean \pm S.D, alongside a Tukey posthoc test to evaluate the significant variations between independent variables, if noted. GraphPad Prism 8.0.2 was used for the analysis of data.

\section{Conclusions}

The present study was aimed at the successful nanoencapsulation of MTX into AEMCS nanoparticles by using the coacervation technique. The encapsulation of MTX in the AEM-CS complex was affirmed by FTIR with nano-size validation by SEM. The study concludes that a developed drug delivery system helps to acquire the efficacious release of the cancer drug model, i.e., MTX. The fabricated nanoparticles showed appreciable encapsulation efficiency and potential to control MTX release till $32 \mathrm{~h}$, especially at tumor $\mathrm{pH}$. Moreover, prepared NPs exhibited substantial cytotoxic results in MCF-7 and MD-MBA231 cancer cell lines. Therefore, the present research provides an idea that the utilization of natural polymers for chemotherapeutics encapsulation can provide a gateway to overcome the side effects associated with cancer drugs with a heightened response to tumor $\mathrm{pH}$, so based on our findings we can say that MTX loaded AEM-CS NPs can be a beneficial route for targeting cancerous cells and that mucilage based NPs could be a striking area for future studies in tumor therapy.

Author Contributions: Conceived, designed and supervised the experiment, S.N. (Sobia Noreen) and S.N.A.B.; Performed the experiment, S.H., B.I. and H.I.; morphology analysis H.H. and A.A.; resources and data curation S.H.; writing-draft preparation, S.H. and S.N. (Shazia Noureen); writing 
reviewing and editing, S.N. (Sobia Noreen), H.E. and M.A.M.E.; animal studies S.A.G.; cytotoxicity analysis and editing B.I. All authors have read and agreed to the published version of the manuscript.

Funding: The authors' work was supported through grant number "375213500" from the Deputyship for Research and Innovation, Ministry of Education in Saudi Arabia.

Institutional Review Board Statement: The study was conducted in accordance with The Pharmacy Research Ethics Committee (PREC), under approval no. 70B18 IAEC/UOS.

Informed Consent Statement: Not applicable.

Data Availability Statement: Not applicable.

Acknowledgments: The authors extend their appreciation to the Deputyship for Research and Innovation, Ministry of Education in Saudi Arabia, and the central laboratory at Jouf University for supporting this study.

Conflicts of Interest: The authors declare no conflict of interest.

\section{References}

1. Du, J.-Z.; Lane, L.A.; Nie, S. Stimuli-responsive nanoparticles for targeting the tumor microenvironment. J. Control. Release 2015, 219, 205-214. [CrossRef]

2. Thomas, R.G.; Surendran, S.P.; Jeong, Y.Y. Corrigendum: Tumor Microenvironment-stimuli responsive nanoparticles for anticancer therapy. Front. Mol. Biosci. 2021, 8, 693909. [CrossRef]

3. De Jong, W.H.; Borm, P.J. Drug delivery and nanoparticles: Applications and hazards. Int. J. Nanomed. 2008, 3, 133. [CrossRef]

4. Haley, B.; Frenkel, E. Nanoparticles for drug delivery in cancer treatment. In Urologic Oncology: Seminars and Original Investigations; Elsevier: Amsterdam, The Netherlands, 2008.

5. Liu, Z.; Jiao, Y.; Wang, Y.; Zhou, C.; Zhang, Z. Polysaccharides-based nanoparticles as drug delivery systems. Adv. Drug Deliv. Rev. 2008, 60, 1650-1662. [CrossRef]

6. Shanmuganathan, R.; Edison, T.N.J.I.; LewisOscar, F.; Kumar, P.; Shanmugam, S.; Pugazhendhi, A. Chitosan nanopolymers: An overview of drug delivery against cancer. Int. J. Biol. Macromol. 2019, 130, 727-736. [CrossRef]

7. Cho, H.-J. Recent progresses in the development of hyaluronic acid-based nanosystems for tumor-targeted drug delivery and cancer imaging. J. Pharm. Investig. 2019, 50, 115-129. [CrossRef]

8. Hu, Q.; Lu, Y.; Luo, Y. Recent advances in dextran-based drug delivery systems: From fabrication strategies to applications. Carbohydr. Polym. 2021, 264, 117999. [CrossRef]

9. Amani, S.; Mohamadnia, Z.; Mahdavi, A. pH-responsive hybrid magnetic polyelectrolyte complex based on alginate/BSA as efficient nanocarrier for curcumin encapsulation and delivery. Int. J. Biol. Macromol. 2019, 141, 1258-1270. [CrossRef]

10. Zhang, Y.; Cui, Z.; Mei, H.; Xu, J.; Zhou, T.; Cheng, F.; Wang, K. Angelica sinensis polysaccharide nanoparticles as a targeted drug delivery system for enhanced therapy of liver cancer. Carbohydr. Polym. 2019, 219, 143-154. [CrossRef] [PubMed]

11. Lu, K.Y.; Li, R.; Hsu, C.H.; Lin, C.W.; Chou, S.C.; Tsai, M.L.; Mi, F.L. Development of a new type of multifunctional fu-coidan-based nanoparticles for anticancer drug delivery. Carbohydr. Polym. 2017, 165, 410-420. [CrossRef]

12. Zaharuddin, N.D.; Noordin, M.I.; Kadivar, A. The use of Hibiscus esculentus (Okra) gum in sustaining the release of propranolol hydrochloride in a solid oral dosage form. BioMed Res. Int. 2014, 2014, 1-8. [CrossRef]

13. Kwak, S.-Y.; Lew, T.T.S.; Sweeney, C.J.; Koman, V.B.; Wong, M.H.; Bohmert-Tatarev, K.; Snell, K.D.; Seo, J.S.; Chua, N.-H.; Strano, M.S. Chloroplast-selective gene delivery and expression in planta using chitosan-complexed single-walled carbon nanotube carriers. Nat. Nanotechnol. 2019, 14, 447-455. [CrossRef]

14. Sheng, J.; Han, L.; Qin, J.; Ru, G.; Li, R.; Wu, L.; Cui, D.; Yang, P.; He, Y.; Wang, J. N-Trimethyl Chitosan Chloride-coated PLGA nanoparticles overcoming multiple barriers to oral insulin absorption. ACS Appl. Mater. Interfaces 2015, 7, 15430-15441. [CrossRef] [PubMed]

15. Hamman, J.H. Chitosan based polyelectrolyte complexes as potential carrier materials in drug delivery systems. Mar. Drugs 2010, 8, 1305-1322. [CrossRef]

16. Ilango, K.; Manisha, M.; Brinda, P. Investigation of colon specificity of novel polysaccharide okra mucilage-film coated with enteric materials. Int. J. Pharma. Bio. Sci. 2012, 3, 53-62.

17. Makhlof, A.; Tozuka, Y.; Takeuchi, H. Design and evaluation of novel pH-sensitive chitosan nanoparticles for oral insulin delivery. Eur. J. Pharm. Sci. 2011, 42, 445-451. [CrossRef] [PubMed]

18. Brar, V.; Kaur, G. Thiolated okra chitosan nanoparticles: Preparation and optimisation as intranasal drug delivery agents. J. Microencapsul. 2020, 37, 624-639. [CrossRef]

19. Cronstein, B.N.; Aune, T.M. Methotrexate and its mechanisms of action in inflammatory arthritis. Nat. Rev. Rheumatol. 2020, 16, 145-154. [CrossRef] [PubMed]

20. Akbari, E.; Mousazadeh, H.; Sabet, Z.; Fattahi, T.; Dehnad, A.; Akbarzadeh, A.; Alizadeh, E. Dual drug delivery of trapoxin A and methotrexate from biocompatible PLGA-PEG polymeric nanoparticles enhanced antitumor activity in breast cancer cell line. J. Drug Deliv. Sci. Technol. 2020, 61, 102294. [CrossRef] 
21. Rahimi, M.; Shojaei, S.; Safa, K.D.; Ghasemi, Z.; Salehi, R.; Yousefi, B.; Shafiei-Irannejad, V. Biocompatible magnetic tris (2aminoethyl) amine functionalized nanocrystalline cellulose as a novel nanocarrier for anticancer drug delivery of metho-trexate. New J. Chem. 2017, 41, 2160-2168. [CrossRef]

22. Zhao, Y.; Guo, Y.; Li, R.; Wang, T.; Han, M.; Zhu, C.; Wang, X. Methotrexate Nanoparticles Prepared with Codendrimer from Polyamidoamine (PAMAM) and Oligoethylene Glycols (OEG) Dendrons: Antitumor Efficacy in Vitro and in Vivo. Sci. Rep. 2016, 6, 28983. [CrossRef] [PubMed]

23. Ciro, Y.; Rojas, J.; Di Virgilio, A.L.; Alhajj, M.J.; Carabali, G.A.; Salamanca, C.H. Production, physicochemical characterization, and anticancer activity of methotrexate-loaded phytic acid-chitosan nanoparticles on HT-29 human colon adenocarcinoma cells. Carbohydr. Polym. 2020, 243, 116436. [CrossRef] [PubMed]

24. Wang, J.; Zhang, Z.; Ai, Y.; Liu, F.; Chen, M.M.; Liu, D. Lactobionic acid-modified thymine-chitosan nanoparticles as po-tential carriers for methotrexate delivery. Carbohydr. Res. 2021, 501, 108275. [CrossRef]

25. Shakeran, Z.; Keyhanfar, M.; Varshosaz, J.; Sutherland, D.S. Biodegradable nanocarriers based on chitosan-modified mesoporous silica nanoparticles for delivery of methotrexate for application in breast cancer treatment. Mater. Sci. Eng. C 2020, 118, 111526. [CrossRef] [PubMed]

26. Bhattacharya, S. Methotrexate-loaded polymeric lipid hybrid nanoparticles (PLHNPs): A reliable drug delivery system for the treatment of glioblastoma. J. Exp. Nanosci. 2021, 16, 345-368. [CrossRef]

27. Malviya, R.; Raj, S.; Fuloria, S.; Subramaniyan, V.; Sathasivam, K.; Kumari, U.; Meenakshi, D.U.; Porwal, O.; Kumar, D.H.; Singh, A.; et al. Evaluation of Antitumor Efficacy of Chitosan-Tamarind Gum Polysaccharide Polyelectrolyte Complex Stabilized Nanoparticles of Simvastatin. Int. J. Nanomed. 2021, 16, 2533-2553. [CrossRef]

28. Gao, C.; Wang, M.; Zhu, P.; Yan, C. Preparation, characterization and in vitro antitumor activity evaluation of hyaluronic acid-alendronate-methotrexate nanoparticles. Int. J. Biol. Macromol. 2020, 166, 71-79. [CrossRef]

29. Boni, F.I.; Almeida, A.; Lechanteur, A.; Sarmento, B.; Cury, B.S.F.; Gremião, M.P.D. Mucoadhesive nanostructured polyelec-trolytes complexes modulate the intestinal permeability of methotrexate. Eur. J. Pharm. Sci. 2018, 111, 73-82. [CrossRef]

30. Priya, K.; Vijayakumar, M.; Janani, B. Chitosan-mediated synthesis of biogenic silver nanoparticles (AgNPs), nanoparticle characterisation and in vitro assessment of anticancer activity in human hepatocellular carcinoma HepG2 cells. Int. J. Biol. Macromol. 2020, 149, 844-852. [CrossRef]

31. De Rosa, I.M.; Kenny, J.M.; Maniruzzaman, M.; Moniruzzaman, M.; Monti, M.; Puglia, D.; Santulli, C.; Sarasini, F. Effect of chemical treatments on the mechanical and thermal behaviour of okra (Abelmoschus esculentus) fibres. Compos. Sci. Technol. 2011, 71, 246-254. [CrossRef]

32. Kajjari, P.B.; Manjeshwar, L.S.; Aminabhavi, T.M. Novel Interpenetrating Polymer Network Hydrogel Microspheres of Chitosan and Poly(acrylamide)-grafted-Guar Gum for Controlled Release of Ciprofloxacin. Ind. Eng. Chem. Res. 2011, 50, 13280-13287. [CrossRef]

33. Seetharaman, S.; Balya, H.; Kuppusamy, G. Preparation and evaluation of cefixime nanoparticles prepared using fenugreek seed mucilage and chitosan as natural polymers. Int. J. Pharm. Clin. Res. 2016, 8, 179-188.

34. da Silva, D.A.; Feitosa, J.P.; Paula, H.C.; de Paula, R.C. Synthesis and characterization of cashew gum/acrylic acid nanoparticles. Mater. Sci. Eng. C 2009, 29, 437-441. [CrossRef]

35. Souza, T.G.F.; Ciminelli, V.S.T.; Mohallem, N.D.S. A comparison of TEM and DLS methods to characterize size distribution of ceramic nanoparticles. J. Physics Conf. Ser. 2016, 733, 012039. [CrossRef]

36. Eaton, P.; Quaresma, P.; Soares, C.; Neves, C.; de Almeida, M.P.; Pereira, E.; West, P. A direct comparison of experimental methods to measure dimensions of synthetic nanoparticles. Ultramicroscopy 2017, 182, 179-190. [CrossRef] [PubMed]

37. Sarmento, B.; Ribeiro, A.; Veiga, F.; Ferreira, D.; Neufeld, R.J. Insulin-Loaded Nanoparticles are Prepared by Alginate Ionotropic Pre-Gelation Followed by Chitosan Polyelectrolyte Complexation. J. Nanosci. Nanotechnol. 2007, 7, 2833-2841. [CrossRef] [PubMed]

38. Brar, V.; Kaur, G. Preparation and Characterization of Polyelectrolyte Complexes of Hibiscus esculentus (Okra) Gum and Chitosan Int. J. Biomater. 2018, 2018, 1-7. [CrossRef]

39. Tian, B.; Liu, S.; Lu, W.; Jin, L.; Li, Q.; Shi, Y.; Li, C.; Wang, Z.; Du, Y. Construction of pH-responsive and up-conversion luminescent NaYF 4: Yb 3+/Er 3+@ SiO 2@ PMAA nanocomposite for colon targeted drug delivery. Sci. Rep. 2016, 6, 1-11.

40. Carrillo-Castillo, T.D.; Castro-Carmona, J.S.; Luna-Velasco, A.; Zaragoza-Contreras, E.A. pH-responsive polymer micelles for methotrexate delivery at tumor microenvironments. E-Polymers 2020, 20, 624-635. [CrossRef]

41. Zhang, Z.-Q.; Pan, C.-H.; Chung, D. Tannic acid cross-linked gelatin-gum arabic coacervate microspheres for sustained release of allyl isothiocyanate: Characterization and in vitro release study. Food Res. Int. 2011, 44, 1000-1007. [CrossRef]

42. Najafipour, A.; Gharieh, A.; Fassihi, A.; Sadeghi-Aliabadi, H.; Mahdavian, A.R. MTX-loaded dual thermoresponsive and pHresponsive magnetic hydrogel nanocomposite particles for combined controlled drug delivery and hyperthermia therapy of cancer. Mol. Pharm. 2020, 18, 275-284. [CrossRef] [PubMed]

43. Alle, M.; Kim, T.H.; Park, S.H.; Lee, S.-H.; Kim, J.-C. Doxorubicin-carboxymethyl xanthan gum capped gold nanoparticles: Microwave synthesis, characterization, and anti-cancer activity. Carbohydr. Polym. 2019, 229, 115511. [CrossRef] [PubMed]

44. Zhang, K.; Gao, J.; Li, S.; Ma, T.; Deng, L.; Kong, Y. Construction of a pH-responsive drug delivery platform based on the hybrid of mesoporous silica and chitosan. J. Saudi Chem. Soc. 2021, 25, 101174. [CrossRef] 
45. Kou, Z.; Dou, D.; Mo, H.; Ji, J.; Lan, L.; Lan, X.; Zhang, J.; Lan, P. Preparation and application of a polymer with pH/temperatureresponsive targeting. Int. J. Biol. Macromol. 2020, 165, 995-1001. [CrossRef] [PubMed]

46. Rahman, M.; Khan, J.A.; Kanwal, U.; Awan, U.A.; Raza, A. Methotrexate-loaded PEGylated gold nanoparticles as hemocompatible and $\mathrm{pH}$-responsive anticancer drug nanoconjugate. J. Nanoparticle Res. 2021, 23, 1-13. [CrossRef]

47. Pandit, A.H.; Mazumdar, N.; Imtiyaz, K.; Alam Rizvi, M.M.; Ahmad, S. Self-Healing and Injectable Hydrogels for Anti-cancer Drug Delivery: A Study with Multialdehyde Gum Arabic and Succinic Anhydride Chitosan. ACS Appl. Bio Mater. 2020, 3, 8460-8470. [CrossRef] [PubMed]

48. Örüm, S.M. Novel cyclomatrix polyphosphazene nanospheres: Preparation, characterization and dual anticancer drug release application. Polym. Bull. 2021, 5, 1-19. [CrossRef]

49. Grassi, M.; Grassi, G. Mathematical Modelling and Controlled Drug Delivery: Matrix Systems. Curr. Drug Deliv. 2005, 2, 97-116. [CrossRef] [PubMed]

50. Bashiri, G.; Shojaosadati, S.A.; Abdollahi, M. Synthesis and characterization of Schiff base containing bovine serum al-bumingum arabic aldehyde hybrid nanogels via inverse miniemulsion for delivery of anticancer drug. Int. J. Biol. Macromol. 2021, 170, 222-231. [CrossRef] [PubMed]

51. Aluigi, A.; Ballestri, M.; Guerrini, A.; Sotgiu, G.; Ferroni, C.; Corticelli, F.; Gariboldi, M.B.; Monti, E.; Varchi, G. Organic sol-ventfree preparation of keratin nanoparticles as doxorubicin carriers for antitumour activity. Mater. Sci. Eng. C 2018, 90, $476-484$. [CrossRef] [PubMed]

52. Sheorain, J.; Mehra, M.; Thakur, R.; Grewal, S.; Kumari, S. In vitro anti-inflammatory and antioxidant potential of thymol loaded bipolymeric (tragacanth gum/chitosan) nanocarrier. Int. J. Biol. Macromol. 2018, 125, 1069-1074. [CrossRef] [PubMed]

53. Abasian, P.; Radmansouri, M.; Jouybari, M.H.; Ghasemi, M.V.; Mohammadi, A.; Irani, M.; Jazi, F.S. Incorporation of magnetic $\mathrm{NaX}$ zeolite/DOX into the PLA/chitosan nanofibers for sustained release of doxorubicin against carcinoma cells death in vitro. Int. J. Biol. Macromol. 2018, 121, 398-406. [CrossRef] [PubMed]

54. Maziero, J.S.; Thipe, V.C.; Rogero, S.O.; Cavalcante, A.K.; Damasceno, K.C.; Ormenio, M.B.; Martini, G.A.; Batista, J.G.; Viveiros, W.; Katti, K.K.; et al. Species-Specific in vitro and in vivo Evaluation of Toxicity of Silver Nanoparticles Stabilized with Gum Arabic Protein. Int. J. Nanomed. 2020, 15, 7359-7376. [CrossRef] [PubMed]

55. Sumaira; Tulain, U.R.; Erum, A.; Hussain, M.A.; Sidra; Malik, N.S.; Rashid, A.; Kausar, R.; Gohar, N.; Shahid, N.; et al. Fabrication, Characterization and Toxicity Evaluation of Chemically Cross linked Polymeric Network for Sustained Delivery of Metoprolol Tartrate. Des. Monomers Polym. 2021, 24, 351-361. [CrossRef]

56. Fathalla, Z.M.; Vangala, A.; Longman, M.; Khaled, K.A.; Hussein, A.; El-Garhy, O.H.; Alany, R.G. Poloxamer-based thermoresponsive ketorolac tromethamine in situ gel preparations: Design, characterisation, toxicity and transcorneal permeation studies. Eur. J. Pharm. Biopharm. 2017, 114, 119-134. [CrossRef]

57. Naveen, N.R.; Kurakula, M.; Gowthami, B. Process optimization by response surface methodology for preparation and evaluation of methotrexate loaded chitosan nanoparticles. Mater. Today: Proc. 2020, 33, 2716-2724. [CrossRef]

58. Nogueira, D.R.; Tavano, L.; Mitjans, M.; Pérez, L.; Infante, M.R.; Vinardell, M.P. In vitro antitumor activity of methotrexate via pH-sensitive chitosan nanoparticles. Biomaterials 2013, 34, 2758-2772. [CrossRef]

59. Agabeigi, R.; Rasta, S.H.; Rahmati-Yamchi, M.; Salehi, R.; Alizadeh, E. Novel chemo-photothermal therapy in breast cancer using methotrexate-loaded folic acid conjugated Au@ SiO2 Nanoparticles. Nanoscale Res. Lett. 2020, 15, 1-14. [CrossRef]

60. Awasthi, R.; Sharma, B.; Kulkarni, G.T. Studies on emulsifying property of mucilages of Hygrophila spinosa and Hibiscus esculentus. Indian J. Nat. Prod. 1985, 1, 3-6.

61. Baveja, S. Examination of natural gums and mucilages as sustaining materials in tablets dosage forms. Ind. J. Pharma. Sci. 1988, 50, 89-92.

62. Douglas, K.L.; Tabrizian, M. Effect of experimental parameters on the formation of alginate-chitosan nanoparticles and evaluation of their potential application as DNA carrier. J. Biomater. Sci. Polym. Ed. 2005, 16, 43-56. [CrossRef] [PubMed]

63. Sharma, H.K.; Lahkar, S.; Nath, L.K. Formulation and in vitro evaluation of metformin hydrochloride loaded microspheres prepared with polysaccharide extracted from natural sources. Acta Pharm. 2013, 63, 209-222. [CrossRef] [PubMed]

64. Almutairi, F.M.; El Rabey, H.A.; Tayel, A.A.; Alalawy, A.I.; Al-Duais, M.A.; Sakran, M.I.; Zidan, N.S. Augmented anticancer activity of curcumin loaded fungal chitosan nanoparticles. Int. J. Biol. Macromol. 2019, 155, 861-867. [CrossRef] [PubMed]

65. Bashir, S.; Aamir, M.; Sarfaraz, R.M.; Hussain, Z.; Sarwer, M.U.; Mahmood, A.; Akram, M.R.; Qaisar, M.N. Fabrication, characterization and in vitro release kinetics of tofacitinib-encapsulated polymeric nanoparticles: A promising implication in the treatment of rheumatoid arthritis. Int. J. Polym. Mater. Polym. Biomater. 2020, 70, 449-458. [CrossRef]

66. Nan, W.; Ding, L.; Chen, H.; Khan, F.U.; Yu, L.; Sui, X.; Shi, X. Topical Use of Quercetin-Loaded Chitosan Nanoparticles Against Ultraviolet B Radiation. Front. Pharmacol. 2018, 9, 826. [CrossRef]

67. Farrell, E.; Brousseau, J.-L. Guide for DLS sample preparation. Brookhaven Instrum. 2014, 1, 1-3.

68. Pollard, M.R.; Sparnacci, K.; Wacker, L.J.; Kerdoncuff, H. Polymer nanoparticle identification and concentration measureMent using fiber-enhanced raman spectroscopy. Chemosensors 2020, 8, 21. [CrossRef]

69. Sohail, R.; Abbas, S.R. Evaluation of amygdalin-loaded alginate-chitosan nanoparticles as biocompatible drug delivery carriers for anticancerous efficacy. Int. J. Biol. Macromol. 2020, 153, 36-45. [CrossRef] 
70. Gooneh-Farahani, S.; Naghib, S.M.; Naimi-Jamal, M.R. A novel and inexpensive method based on modified ionic gelation for $\mathrm{pH}$-responsive controlled drug release of homogeneously distributed chitosan nanoparticles with a high encapsulation ef-ficiency. Fibers Polym. 2020, 21, 1917-1926. [CrossRef]

71. Seo, D.-H.; Jeong, Y.-I.; Kim, D.-G.; Jang, M.-J.; Jang, M.-K.; Nah, J.-W. Methotrexate-incorporated polymeric nanoparticles of methoxy poly(ethylene glycol)-grafted chitosan. Colloids Surf. B Biointerfaces 2009, 69, 157-163. [CrossRef]

72. Chickpetty, S.M.; Raga, B.V. Formulation, in vitro drug release and in vivo human X-ray investigation of polysaccharide based drug delivery systems for targeting 5-fluorouracil to the colon. Braz. J. Pharm. Sci. 2013, 49, 263-273. [CrossRef] 